\title{
Cyclones and fabric filters dusts from secondary aluminium flue gases: a characterization and leaching study
}

\author{
P. E. Tsakiridis ${ }^{1,3} \cdot$ P. Oustadakis ${ }^{1} \cdot$ K. Moustakas $^{2,3} \cdot$ S. L. Agatzini ${ }^{1}$
}

Received: 8 March 2016/Revised: 15 April 2016/Accepted: 3 May 2016/Published online: 10 May 2016

(C) Islamic Azad University (IAU) 2016

\begin{abstract}
The present work aims at the characterization and leachability examination of aluminium dusts, generated during the secondary aluminium production from scrap. Two different types of dusts were examined: a cyclone aluminium dust and a fabric filter aluminium dust, derived from the waste gases de-dusting system, produced during the Al scrap meltdown. The characterization of both dusts was carried out using particle size distribution analysis, chemical analysis, X-ray diffraction and thermogravimetric/differential thermal analyses. Their microstructure and morphological characteristics were examined by scanning electron microscopy and transmission electron microscopy. The results showed that the basis of the examined dusts was different, as they consisted of different mixtures of metallic aluminium, salt flux constituents, aluminium oxide and aluminium nitrides. Their behaviour during leaching was determined by the toxicity characteristic leaching procedure test and the EN 12457-2 compliance leaching test. The results revealed that both dusts should be treated as hazardous wastes and in case of landfilling they should be disposed of at appropriate, regulation-prescribed waste dumps, after removing the watersoluble phases, such as chlorides or nitrides.
\end{abstract}

P. E. Tsakiridis

ptsakiri@central.ntua.gr

1 Laboratory of Metallurgy, School of Mining and Metallurgical Engineering, National Technical University of Athens, 9 Heroon Polytechniou St, 15780 Athens, Greece

2 Unit of Environmental Science and Technology, School of Chemical Engineering, National Technical University of Athens, 9 Heroon Polytechniou St, 15773 Athens, Greece

3 School of Science and Technology, Waste Management, Hellenic Open University, Parodos Aristotelous 18, 26335 Patra, Greece
Keywords Secondary aluminium dust - Cyclones · Fabric filters $\cdot$ Characterization $\cdot$ Leachability

\section{Introduction}

Aerospace, transportation, architectural construction and marine engineering are some of the most important sectors, in which aluminium is widely used in a variety of applications, mainly because of its exceptional mechanical and corrosion-resistant properties, in combination with its very low specific weight (about 1/3 of iron). Today, aluminium is produced either as "primary aluminium" during the hydrothermal treatment of bauxite and the alumina electrolytic reduction in a cryolite bath, or as "secondary aluminium", after scrap recycling and reprocessing of used aluminium products. In the late 1990s, the aluminium production reached 28 million tonnes, from which over 8 million tonnes derived from the secondary recycling industry. In 2010, the total Al-metal amount increased to 56 million tonnes (18 million tonnes from $\mathrm{Al}$ scrap), whereas the aluminium demand by 2020 is expected to have increased to around 97 million tonnes, with 31 million tonnes being produced from recycling scrap (International Aluminium Institute 2013).

The typical feedstock in the secondary aluminium industry is a complex combination of different types of aluminium process scraps, and it may consist of used beverage cans (UBCs), foils, extrusions, commercial scraps, turnings and old rolled or cast metal (Tenorio and Espinosa 2002). The feedstock is loaded, after balancing with suitable quantities of primary metallic $\mathrm{Al}$ into melting furnaces (reverberatory or rotary furnaces). The melt process in case of rotary melting furnaces, whose capacity varies from 0.5 to 0.7 tonnes per hour, in melting temperatures at around 
$700-750{ }^{\circ} \mathrm{C}$, is carried out under a protective layer of salt (mixture of $\mathrm{NaCl} / \mathrm{KCl}$ with cryolite and/or $\mathrm{CaF}_{2}$ ), targeting primarily at protecting the aluminium melt from oxidation loss and secondly in absorbing the oxides and contaminants from the scrap (European Aluminium Association 2004; Unger and Beckmann 1992). On the other hand, gas- or oilfired reverberatory furnaces present much higher capacities (15 to over 45 tonnes) (Wernick and Themelis 1998). The scrap loading is usually carried to the metal pool with the salt flux, in order to create a protective layer from oxidation, thus improving the agglomeration, separation and recovery of the metal from the scrap.

The waste gases produced during the scrap meltdown usually present temperatures of about $1000{ }^{\circ} \mathrm{C}$ (Shinzato and Hypolito 2005). Many components of the charge, including aluminium phases and salt flux, entered the vapour phase, from which they are fumed off, cooled and collected in the off-gas cleaning system, generating large quantities of dust. One of the most important unit operations in the secondary aluminium industry is the gas stream "de-dusting" process. In most cases, the larger dust particles are removed by mechanical pre-collectors (gravity, inertial and centrifugal separators), such as cyclones, which are typical mass force separators, before the gas enters a bag filter (an adhesion force separator), or a hot electrostatic precipitator.

Regarding cyclones, which are characterized by the particle cut diameter, the flue gas and the particles are introduced into a cylinder in order to obtain a rotational movement. The particles shift to the cylinder wall due to centrifugal forces, and then to the vortex chamber. The recovered dust is concentrated to the collection chamber. Cyclone separators are most efficient for particles with a diameter above 20 microns. This off-gas cleaning system operating temperature is usually in the range of 350-400 ${ }^{\circ} \mathrm{C}$ (Strauss 1975; Peukert and Wadenpohl 2001).

When higher particle recovery efficiency is required, fabric baghouse filter has to be used, where the removal of the particles is carried out during the passage of the waste gases either by deflection (mass forces) or by diffusion (adhesion forces). The combination of these forces gives an exceptional performance in excess of 99.0 or $99.9 \%$, for most kinds of dusts, regardless of the particle size (from submicron to several hundred microns) (Dirgo and Cooper 1983). Common fabric filters usually operate up to $250{ }^{\circ} \mathrm{C}$, while in the case where higher temperatures are required, special materials should be used in their construction. The dust cake forming on the filter is removed regularly by shaking, pulsing or gas-reversing (Vallero 2008).

The quantity and the chemical composition of the dusts produced vary considerably according to the type and the quality of the scrap and the technology applied. Depending on the scrap mix, the amount of dust produced per ton of secondary aluminium ranges from 3 to $13 \mathrm{~kg}$ and it is the second-largest solid waste generated, as the amount of black dross produced per ton of secondary aluminium ranges from 200 to $300 \mathrm{~kg}$, whereas in case of rotary furnaces the amount of salt slag produced varies from 300 to $500 \mathrm{~kg}$ (The Aluminium Association 2013; Tsakiridis et al. 2013).

Although there are few reports on black dross or/and salt slag characterization and management, the so far published literature has given little attention to the characterization and leachability of aluminium dusts derived from secondary aluminium furnace flue gases. They may contain 3-5 wt $\%$ metallic aluminium, 25-30 wt\% salt flux constituents, while $50-70 \mathrm{wt} \%$ of it consists primarily of aluminium oxide and aluminium nitrides. Except oxides, other contaminants in lower quantities, such as carbides, sulphides and phosphides, are also present (Huang et al. 2015; López et al. 2001; López-Delgado et al. 2009). Due to their properties, they have been classified as hazardous wastes according to the European Catalogue for Hazardous Wastes (European Waste Catalogue 2002). They are considered as highly irritant (H4), harmful (H5) and leachable (H13). However, the main problem is their high reactivity with water (H12), leading to the formation of toxic, explosive, poisonous and unpleasant odorous gases, such as hydrogen, ammonia, methane and hydrogen sulphide (Tsakiridis 2012). The disposal of such wastes has become a serious problem in recent years. In case of co-disposal with municipal solid waste in common landfills, high concentrations of hydrogen together with gaseous ammonia have been reported (Huang et al. 2015; Calder and Stark 2010).

The aim of the present research work is to present the results on the complete characterization and the leachability examination of cyclone and fabric filter dusts, generated during the scrap meltdown in the secondary aluminium production. Chemical analysis, X-ray diffraction, thermal analysis, scanning electron microscopy and transmission electron microscopy were used in order to characterize both dusts, whereas their leachability evaluation was carried out by the toxicity characteristic leaching procedure (1992) test and the EN 12457-2 (2003) compliance leaching test. The present research was carried out in the Mining and Metallurgical Engineering School of the National Technical University of Athens (September-December 2015).

\section{Materials and methods}

\section{Aluminium dusts characterization}

The dusts under investigation were generated by a secondary aluminium plant in Greece and typically consist of the coarser cyclone aluminium dust (CAD), collected by the cyclone separators, and the finer fabric filter aluminium 
dust (FAD) that has been captured by the fabric filters. The coarser CAD was grey, while the finer FAD appeared black in colour. Their particle size distribution was determined by a laser scattering particle size distribution analyser (Cilas: Model 1064). An amount of $0.1 \mathrm{~g}$ of powdered sample was added in $100 \mathrm{ml}$ of ethanol and underwent dispersion treatment by an ultrasonic dispersion unit for 60 s. Chemical analyses were carried out with X-ray fluorescence (Spectro-Xepos), atomic absorption, spectrophotometry (Perkin Elmer 4100) and inductively coupled plasma mass spectrometry (ICP-MS X Series II, Thermo Scientific). The mineralogical phases were determined by XRD analysis, using a Bruker D8-Focus diffractometer with nickel-filtered $\mathrm{CuKa}$ radiation $(\lambda=1.5406 \AA)$, at $40 \mathrm{kV}$ and $40 \mathrm{~mA}$. Semi-quantitative phases analysis was carried out by TOPAS software (Bruker-AXS), based on Rietveld algorithm. TG/DTA analysis was conducted with a Setaram-Labsys thermal analyser. Samples were placed in ceramic crucibles and heated from room temperature to $1000{ }^{\circ} \mathrm{C}$ at a heating rate of $5{ }^{\circ} \mathrm{C} /$ min using $\mathrm{N}_{2}$ as a medium under static condition. The morphology of both dusts was examined by scanning electron microscopy (SEM) using a Jeol 6380LV scanning electron microscope. Spot chemical analysis of samples particles was carried out by an Oxford INCA energy-dispersive spectrometer (EDS) connected to the SEM. Finally, TEM measurement was conducted with a high resolution JEOL JEM-2100, operating at $200 \mathrm{kV}$, equipped with an Oxford X-Max 100 EDS detector.

\section{Leachability tests}

Both dusts were subjected to the toxicity characteristic leaching procedures (TCLP) test, in order to determine the heavy metals leachability, simulating the scenario of a common landfill under laboratory conditions (US EPA 1992). The extraction solution was prepared using glacial acetic acid to obtain a $\mathrm{pH}$ value of 2.88 . The dust samples and acetic acid solution were placed into beakers with liquid/solid ratio of 20:1 and extracted for $18 \mathrm{~h}$.

Furthermore, the batch test EN 12457-2 (2003) leaching procedure, which is performed on materials with particle size below $4 \mathrm{~mm}$, was also carried out, in order to assess what type of landfill site (for inert, non-hazardous or hazardous wastes) is suitable for the examined dusts disposal. The test was conducted in a batch reactor, by mixing the waste with deionized water with continuous stirring (10 rpm) for $24 \mathrm{~h}$ at a controlled temperature value equal to $20 \pm 5{ }^{\circ} \mathrm{C}$ in a solid/liquid ratio of $1: 10$, followed by filtration and determination of dissolved elements. The results of the applied test were compared with the regulatory limits issued by the European Council (2003).

\section{Results and discussion}

\section{Aluminium dusts characterization}

The particle size distribution, namely the determination of the relative contribution of each fraction of the sample, of both aluminium dusts captured by cyclone and bag filter collectors is shown in Fig. 1. The expected alterations in particle size and specific surface area between CAD and FAD are evident, although both dusts consisted of very fine grain size, a characteristic that contributes to their hazardousness. Regarding CAD, about $90 \mathrm{wt} \%$ of it exhibits a grain size smaller than $80 \mu \mathrm{m}$, whereas the $50 \mathrm{wt} \%$ was below $22 \mu \mathrm{m}$. It presented a relatively heterogeneous distribution of particle size and contained two major size fractions with a minor one: a very fine-grained portion $(0.15-1.0 \mu \mathrm{m})$ and two coarser parts $(\approx 1.0-10$ and $20-100 \mu \mathrm{m})$. Its finer content is relatively low, and it was estimated at about $1 \mathrm{wt} \%$. The generation of the finer particles should be attributed not only to evaporation/condensation phenomena, but also to the flue gas velocity, whereas the larger particles probably derived from the fragmentation of the salt flux, black dross and trapped metallic aluminium formed during the scrap meltdown step. This particle size diminution could also be observed in the scanning electron microscopy micrographs shown in Fig. 4.

On the other hand, a finer particle size was observed in the case of FAD. Its particle size distribution ranged from 0.09 to $42 \mu \mathrm{m}$, with $90 \mathrm{wt} \%$ of the powder under $13.5 \mu \mathrm{m}$, whereas $50 \mathrm{wt} \%$ of it was below $3.6 \mu \mathrm{m}$. The particle size distribution in this case appears to be bimodal. The smallest first mode is located at $0.2 \mu \mathrm{m}$, whereas the second mode at around $5 \mu \mathrm{m}$. The first mode $(20 \%)$ was below $1 \mu \mathrm{m}$, the submicron fraction, which is probably derived from evaporation and condensation phenomena and the second one (the majority of the particles) with diameter larger than one micron (the supermicron fraction).

As it was mentioned above, the chemical and mineralogical composition of the examined dusts depends mainly on the quality of $\mathrm{Al}$ scrap processed, the operating conditions and the type of technology and furnace applied for Al-metal production. The dusts chemical analyses are given in Table 1, where the main elements content is presented in oxides (wt\%) and the corresponding of trace elements in $\mathrm{mg} / \mathrm{kg}$.

In the case of $\mathrm{CAD}$, aluminium was the main constituent and accounted for $41.76 \mathrm{wt} \%$ (as oxide) of the dust mass. Besides aluminium, the dust is characterized by the relatively high content of calcium, whose presence is contiguous in both dusts, resulting from the lime used for the gases neutralization. The presence of alkalis was relatively low, as small amounts of $\mathrm{Na}_{2} \mathrm{O}(2.62 \mathrm{wt} \%)$ and $\mathrm{K}_{2} \mathrm{O}$ $(0.44 \mathrm{wt} \%)$ were detected. On the other hand, FAD mainly 


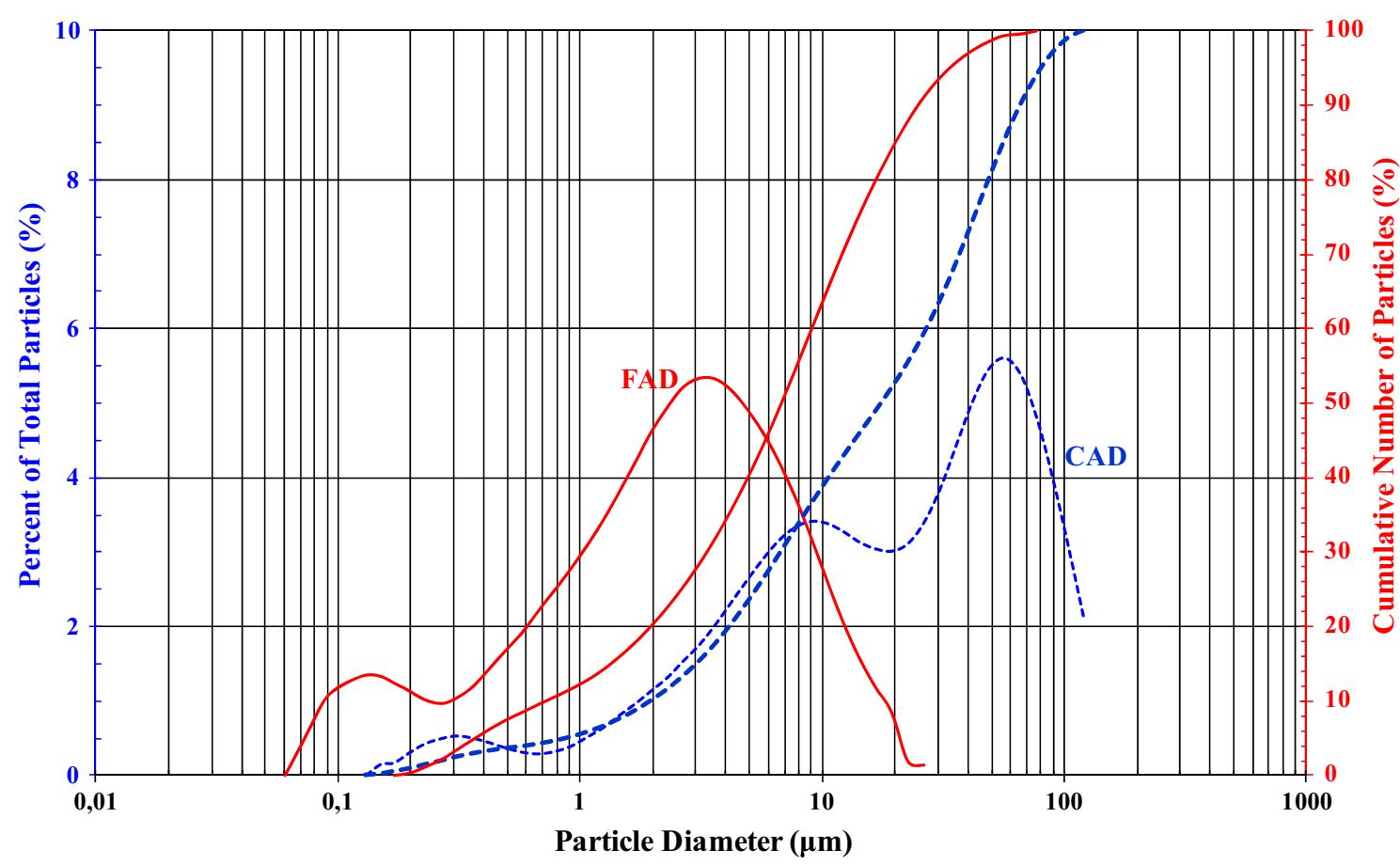

Fig. $1 \mathrm{CAD}$ and FAD particle size distribution (cumulative passing and particle distribution)

Table $1 \mathrm{CAD}$ and FAD chemical analysis

\begin{tabular}{|c|c|c|}
\hline Constituents & CAD & FAD \\
\hline \multicolumn{3}{|c|}{ Major elements (wt\%) } \\
\hline $\mathrm{SiO}_{2}$ & 3.98 & 6.17 \\
\hline $\mathrm{Al}_{2} \mathrm{O}_{3}$ & 41.76 & 12.61 \\
\hline $\mathrm{Fe}_{2} \mathrm{O}_{3}$ & 1.17 & 3.93 \\
\hline $\mathrm{CaO}$ & 21.02 & 22.80 \\
\hline $\mathrm{MgO}$ & 6.18 & 5.31 \\
\hline $\mathrm{K}_{2} \mathrm{O}$ & 0.44 & 2.44 \\
\hline $\mathrm{Na}_{2} \mathrm{O}$ & 2.62 & 9.74 \\
\hline $\mathrm{TiO}_{2}$ & 2.24 & 0.33 \\
\hline $\mathrm{ZnO}$ & 0.53 & 1.31 \\
\hline $\mathrm{BaO}$ & 1.03 & 0.34 \\
\hline $\mathrm{SO}_{3}$ & 1.14 & 0.77 \\
\hline $\mathrm{P}_{2} \mathrm{O}_{5}$ & 0.12 & 0.33 \\
\hline \multicolumn{3}{|c|}{ Trace elements (mg/kg) } \\
\hline As & 7.4 & 9.5 \\
\hline $\mathrm{Cd}$ & 11.5 & 81.6 \\
\hline $\mathrm{Co}$ & 109 & 24 \\
\hline $\mathrm{Cr}$ & 164 & 101 \\
\hline $\mathrm{Cu}$ & 328 & 194 \\
\hline $\mathrm{Mn}$ & 652 & 324 \\
\hline $\mathrm{Ni}$ & 162 & 49 \\
\hline Sn & 298 & 858 \\
\hline $\mathrm{Pb}$ & 598 & 5510 \\
\hline
\end{tabular}

composed of aluminium, calcium and sodium. In this case, the presence of alkalis is much higher, reaching about $12 \mathrm{wt} \%$. The analysis of the trace elements showed that the concentrations of heavy metals were relatively high in both dusts. However, the bag filter dust contained higher $\mathrm{Pb}, \mathrm{Zn}$, $\mathrm{Sn}$, and $\mathrm{Cd}$ than cyclone dust did and the former has lower contents of $\mathrm{Co}, \mathrm{Ni}, \mathrm{Cr}$ and $\mathrm{Cu}$ than the latter has. This should be attributed to the fact that, in contrast to the other metals, much more phases that contained $\mathrm{Pb}, \mathrm{Zn}, \mathrm{Sn}$, and $\mathrm{Cd}$ had been easily volatized during the melting process, being present in the flue gas with the form of vapours. Subsequently, after passing through a cooler, they were condensed forming finer particles of mixed oxides, which are easily trapped in the final FAD.

The X-ray diffraction patterns of both CAD and FAD are presented in Fig. 2. The semi-quantitative determination of the principal phases was carried out by Rietveld analysis technique (Table 2), taking into account the assumption that the sum of the identified crystalline phases has to add up to $100 \%$.

However, the above concern is not always precise because of the possible presence of amorphous phases or other constituents with low response, whose concentrations are relatively low. In the case of $\mathrm{CAD}$, five major phases were identified: corundum $\left(\mathrm{Al}_{2} \mathrm{O}_{3}\right)$, spinel $\left(\mathrm{MgAl}_{2} \mathrm{O}_{4}\right)$, calcite $\left(\mathrm{CaCO}_{3}\right)$, halite $\mathrm{NaCl}$ and metallic $\mathrm{Al}$. The corundum derived from the reaction of the atmospheric oxygen 


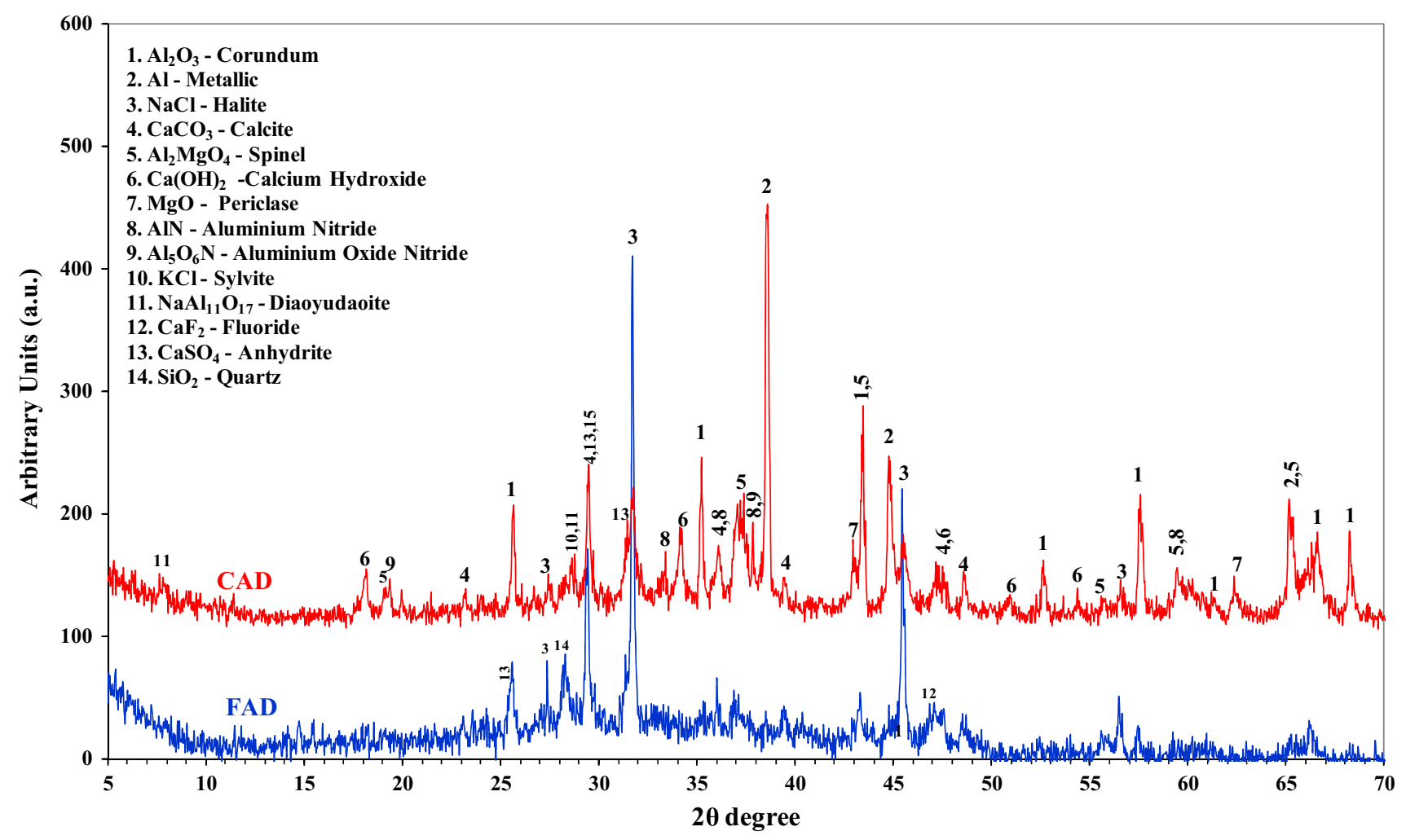

Fig. $2 \mathrm{CAD}$ and FAD mineralogical phases

Table 2 CAD and FAD phase composition by Rietveld analysis

\begin{tabular}{|c|c|c|}
\hline \multirow[t]{2}{*}{ Phases } & \multicolumn{2}{|c|}{ Composition (wt \%) } \\
\hline & CAD & FAD \\
\hline $\mathrm{Al}_{2} \mathrm{O}_{3}-$ Corundum & 16.2 & 15.3 \\
\hline Al-Metallic & 14.5 & 2.2 \\
\hline $\mathrm{MgAl}_{2} \mathrm{O}_{4}-$ Spinel & 15.2 & 3.3 \\
\hline AlN_-Aluminium Nitride & 4.7 & 2.6 \\
\hline $\mathrm{Al}_{5} \mathrm{O}_{6} \mathrm{~N}$-Aluminium Oxide Nitride & 5.6 & - \\
\hline $\mathrm{NaCl}$ - Halite & 10.3 & 18.3 \\
\hline $\mathrm{KCl}$ —Sylvite & 1.1 & 4.6 \\
\hline $\mathrm{CaCO}_{3}$ - Calcite & 16.8 & 33.1 \\
\hline $\mathrm{Ca}(\mathrm{OH})_{2}$-Calcium Hydroxide & 6.9 & - \\
\hline $\mathrm{MgO}$-Periclase & 2.2 & 2.4 \\
\hline $\mathrm{NaAl}_{11} \mathrm{O}_{17}$-Diaoyudaoite & 0.9 & - \\
\hline $\mathrm{CaF}_{2}$-Fluoride & 1.1 & 5.2 \\
\hline $\mathrm{SiO}_{2}-$ Quartz & 1.2 & 6.5 \\
\hline $\mathrm{CaSO}_{4}$-Anhydrite & 3.2 & 6.4 \\
\hline
\end{tabular}

with metallic aluminium, during the melting process at high temperatures. $\mathrm{MgAl}_{2} \mathrm{O}_{4}$ is the result of oxidation of magnesium present in the aluminium scrap as an alloying element, during the metal melting. The presence of $\mathrm{CaCO}_{3}$ should be attributed to the partial carbonization of lime used for the gases neutralization. Halite, together with $\mathrm{KCl}$ and $\mathrm{CaF}_{2}$, derived from the salt flux used during the melting process, in order to protect the metal from the reactive atmosphere. Aluminium nitride (AlN) and aluminium oxide nitride $\left(\mathrm{Al}_{5} \mathrm{O}_{6} \mathrm{~N}\right)$ are also present in relative high proportion, generated due to the nitrogen and/or oxygen combination with aluminium, during its melting process in air. On the other hand, the abundance of $\mathrm{NaCl}$ in FAD was the most striking difference, between CAD and FAD. The high content of $\mathrm{NaCl}$ should also be attributed to off-gases scrubbing with $\mathrm{NaOH}$, in order to remove the rest of chlorides produced from the salt flux. Fine particles of $\mathrm{NaCl}$ are formed, which are then trapped in fabric filters, developing a particle cake over the filter. And in this case, a considerable amount of $\mathrm{CaCO}_{3}$ is also detected, due to the reaction of $\mathrm{CO}_{2}$ with lime.

The results of the thermogravimetric (TG) analysis and the differential thermal analysis (DTA) of both dusts are presented in Fig. 3. The total mass loss of CAD calculated at $1000{ }^{\circ} \mathrm{C}$ was about $20 \%$, whereas the corresponding of FAD reached at $22 \%$. TG-DTA diagrams for both dusts showed four steps for the weight loss, in the range of $30-750{ }^{\circ} \mathrm{C}$. The first one occurred in the range of 30-130 C, corresponding to the evaporation of physically adsorbed water, whereas the second one (endothermic peaks at $280{ }^{\circ} \mathrm{C}$ ) should be attributed to the loss of chemically adsorbed water due to dehydroxylation reactions and water 
removal. The third endothermic peak at $500{ }^{\circ} \mathrm{C}$ on the DTA curves is associated with the dehydration and the decomposition of $\mathrm{Ca}(\mathrm{OH})_{2}$, whereas the fourth one (heat absorbance in the range of $750{ }^{\circ} \mathrm{C}$ ) should be attributed mainly to the release of $\mathrm{CO}_{2}$ during the carbonates decomposition. It should be noticed that in the case of CAD, a strong exothermic peak $\left(650{ }^{\circ} \mathrm{C}\right)$ was observed, which is associated with the melting of metallic aluminium trapped in this fraction from cyclones. On the other hand, regarding FAD, above $750{ }^{\circ} \mathrm{C}$, continuous weight loss (about $3 \%$ ) was observed possibly because of the volatilization phenomena of heavy metals, such as $\mathrm{Pb}$ and $\mathrm{Zn}$.

$\mathrm{CAD}$ and FAD were examined by scanning electron microscopy (SEM) using secondary and backscattered electron detectors, in conjunction with energy-dispersive spectroscopy (EDS), in order to gain further knowledge about the dusts mineralogical phases and morphology. The CAD particles appeared as spherical particles or elongated grains of various sizes $(10-150 \mu \mathrm{m})$, whereas some spherical fine-grained particles $(0.5-3.0 \mu \mathrm{m})$ were also present (Fig. 4). The finer particles appeared to form aggregates or to cover the larger particles, suggesting agglomeration morphology. CAD is characterized by the relatively high presence of spheroid metallic aluminium, which in some cases was entrapped inside the oxide grains. Corundum was detected with the form of well-defined spherical particles, whereas spinel $\left(\mathrm{MgAl}_{2} \mathrm{O}_{4}\right)$ with the form of larger spherical particles with wrinkled surface. Aluminium nitrides were detected with the form of both fibrous and/or elongated crystals, whereas high density of hexagonal plates of $\mathrm{Ca}(\mathrm{OH})_{2}$ was also observed, whose presence was attributed to the lime used for the gases neutralization. Additionally, well-defined particles of calcium carbonates were found, which had been produced as a result of partial carbonation of lime.

Regarding FAD, an agglomerated morphology was predominant with fine particles forming aggregates or covering larger particles. Fragile aggregates of fine crystallites were detected, which seem to be separated easily, indicating a lower temperature agglomeration (Fig. 5). The aggregates presented an irregular shape and a relatively homogeneous size of about 30-50 $\mu \mathrm{m}$. They comprised mostly of smooth calcite particles of spherical shape, mainly due to the lime carbonation. The main part of the particles with size less than $1 \mu \mathrm{m}$ was aluminium oxide, which had been formed during the oxidation of metallic Al droplets. Those fine particles have formed coarse grains, whose morphology mainly composed of aggregates either due to agglomeration phenomena, or as they have covered larger particles. The high presence of halite was also confirmed, mainly with the form of pseudo-cubic plates with rounded sides.

The above result was also confirmed by TEM examination of FAD particles (Fig. 6). Most of the finer part of the particles presented a subrounded to subangular morphology, very often consisting of a wide size distribution, ranging from $10 \mathrm{~nm}$ to $1-2 \mu \mathrm{m}$. In most cases, the dust particles had formed larger aggregates, but also separate nanoparticles could frequently be distinguished. Some of the grains presented a cubic structure, which is indicative of the chloride phases, such as halite, whereas the coarse

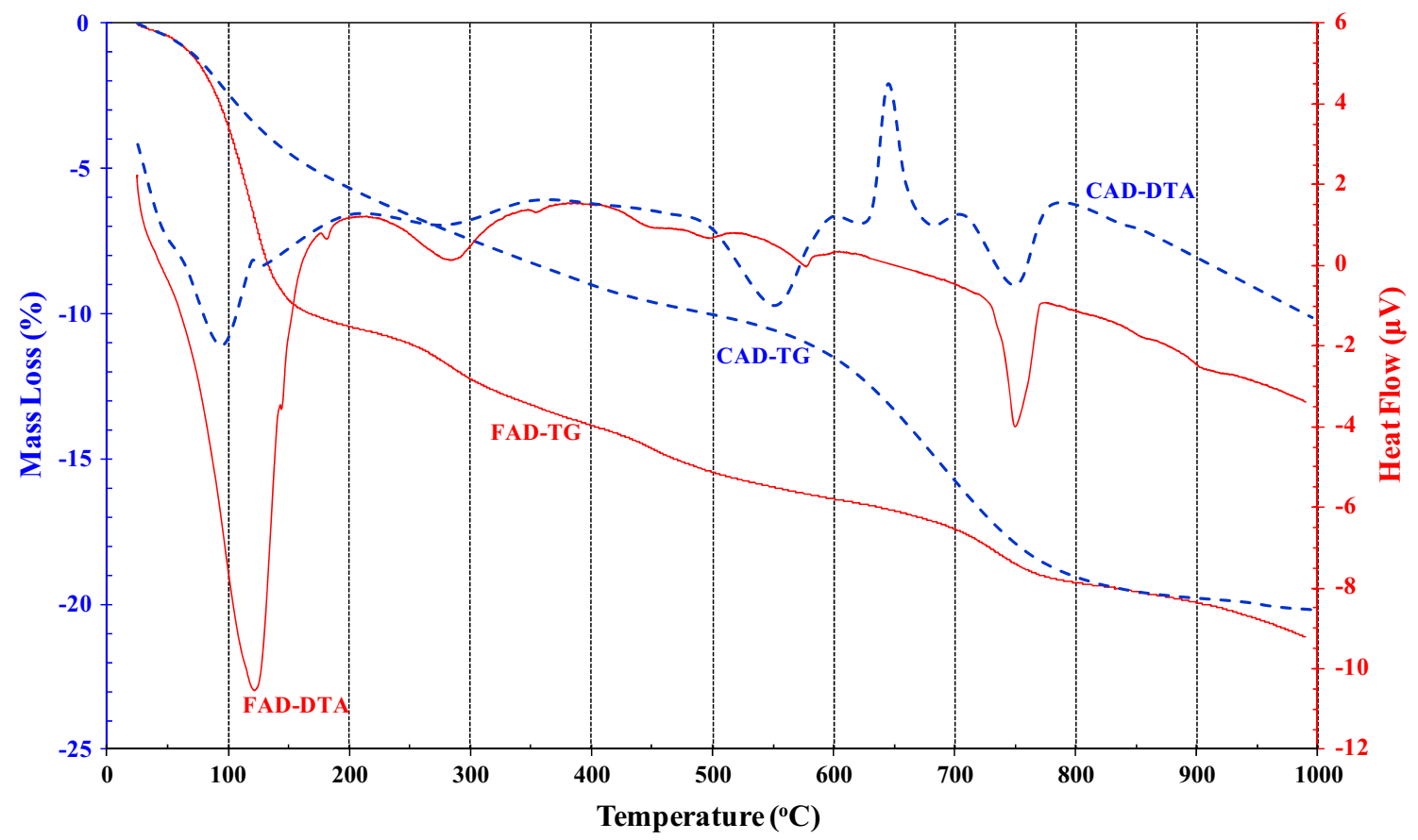

Fig. 3 TG-DTA curves of CAD and FAD 

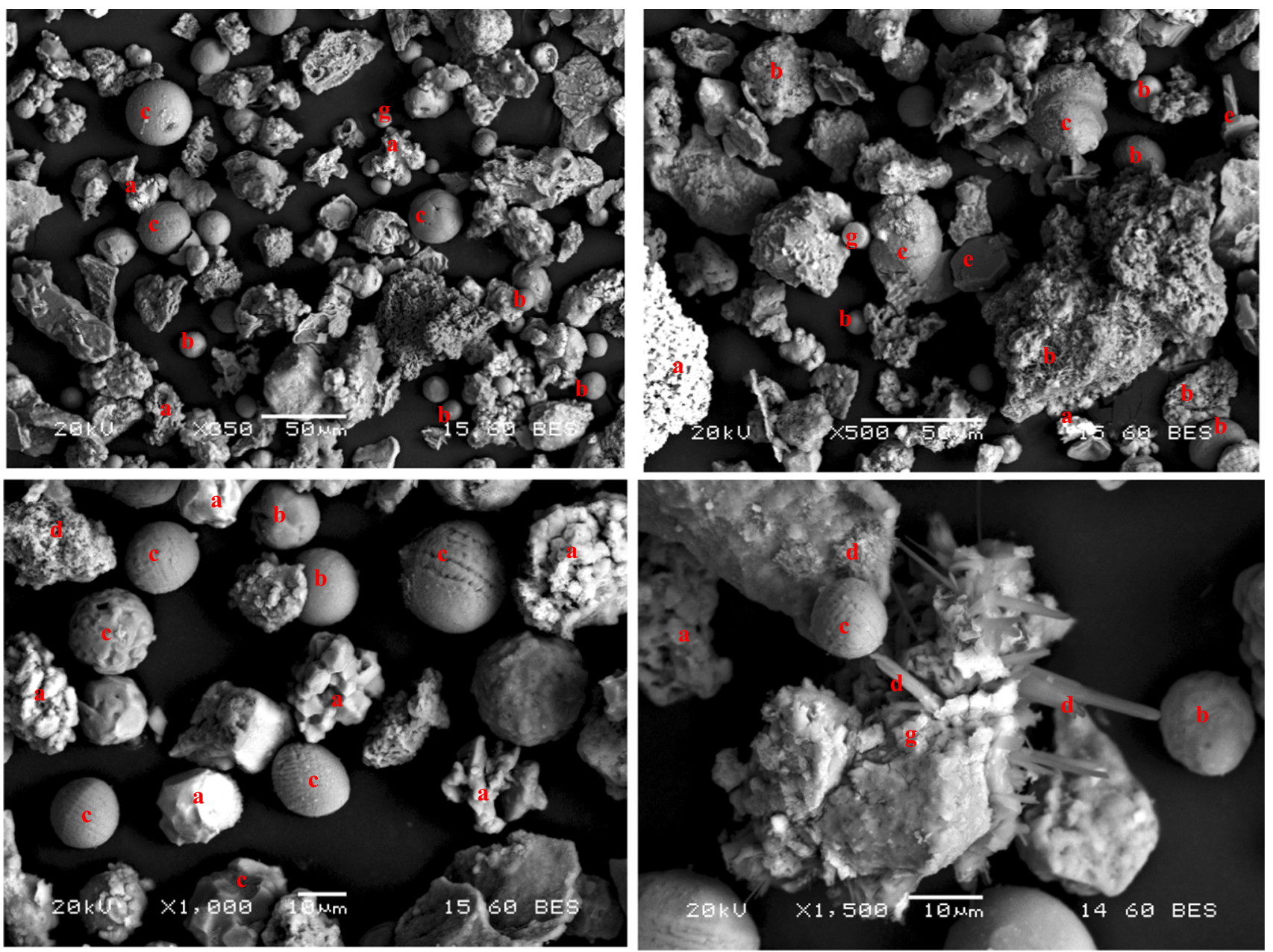

Fig. 4 Scanning electron microscopy micrographs of the as-received CAD. $a$ Metallic $\mathrm{Al}, b \mathrm{Al}_{2} \mathrm{O}_{3}, c \mathrm{MgAl}_{2} \mathrm{O}_{4}, d \mathrm{AlN} / \mathrm{Al}_{5} \mathrm{O}_{6} \mathrm{~N}, e \mathrm{Ca}(\mathrm{OH})_{2}$, $g \mathrm{CaCO}_{3}$

grains with rhombohedral morphology were attributed to the presence of carbonate minerals, such as calcite. The detection of fibbers longer than $500 \mathrm{~nm}$ in length confirmed the presence aluminium nitrides, whose size is much smaller in case of FAD.

\section{Leachability tests}

As it has been mentioned above, the aluminium dusts derived from the waste gases de-dusting system have been classified as hazardous wastes (European Waste Catalogue 2002) mainly due to their high reactivity with water, which can result in the formation of toxic and harmful gases $\left(\mathrm{NH}_{3}, \mathrm{H}_{2}, \mathrm{PH}_{3}\right.$, etc.). In order to examine heavy metals leachability, the cyclone aluminium dust and the corresponding from the fabric filter were subjected to the toxicity characteristic leaching procedure test, thus simulating their leachability in case of disposal in sanitary landfills together with other municipal wastes. Both dusts were analysed for ten metals (cadmium, lead, arsenic, barium, chromium, aluminium zinc, nickel, cobalt and copper), and the results are presented in Table 3 along with the corresponding limits.

Regarding CAD, the heavy metals concentrations in the leach liquor were found to be below the regulatory limits defined by US EPA for non-hazardous waste. All metals presented relatively limited extraction in TCLP solution, except $\mathrm{Al}$ and $\mathrm{Zn}$. Aluminium extraction is significantly higher (no regulatory limit is available), mainly due to the leaching of the aluminium-rich phases (especially aluminium nitrides) contained in the dust, a fact that should also be taken into account during the dust management/disposal.

On the other hand, according to the FAD heavy metals chemical analysis, it is obvious that it presents higher potential to exhibit toxicity characteristics than CAD. This observation was confirmed as cadmium and lead (mainly coming from the paints found on the $\mathrm{Al}$ scrap surface) presented greater affinity for the acetate ions and their values in the leach liquor were found to be above the corresponding EPA limits. The high presence of those 

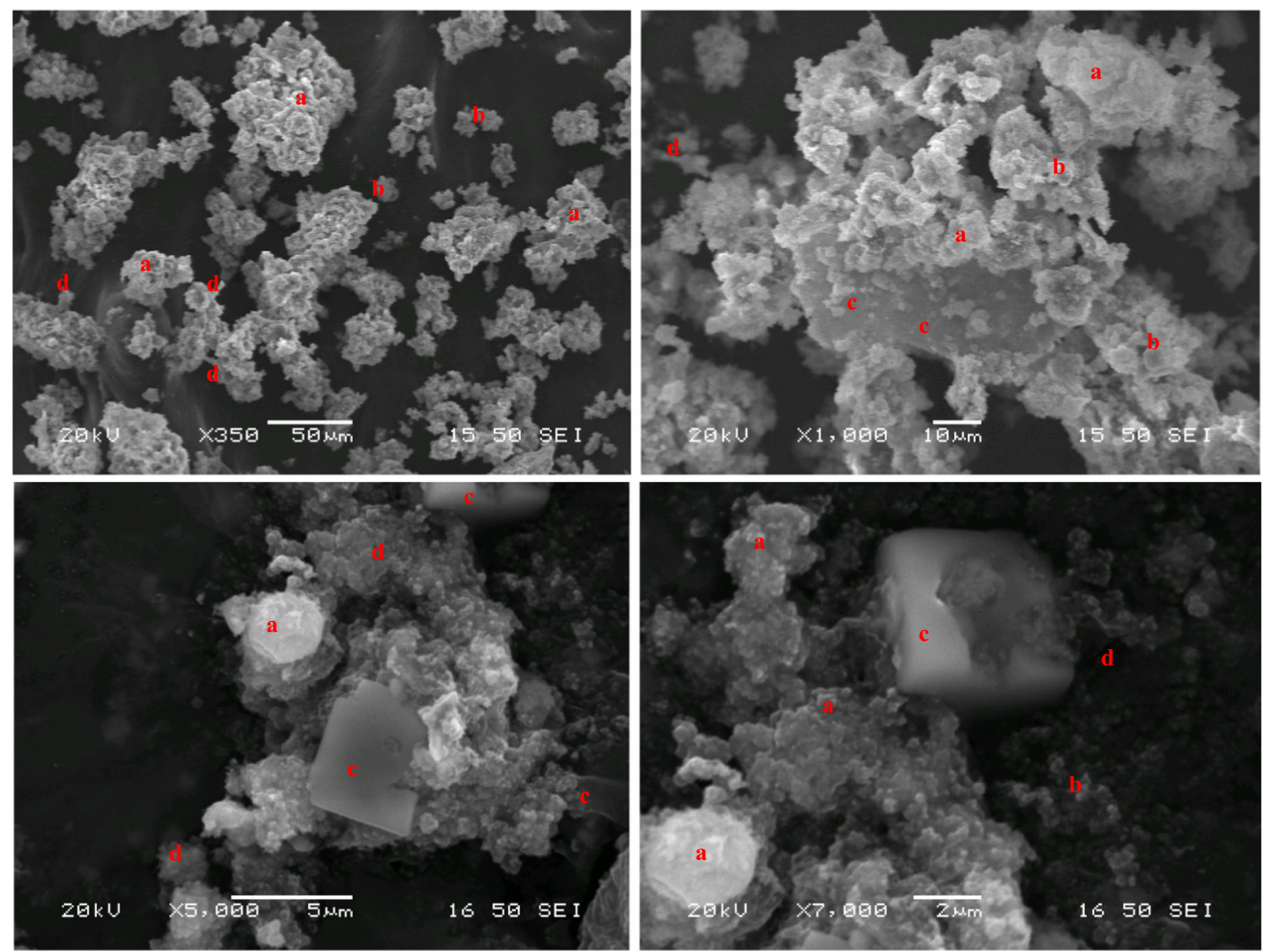

Fig. 5 Scanning electron microscopy micrographs of the as-received FAD. $a \mathrm{CaCO}_{3}, b \mathrm{Al}_{2} \mathrm{O}_{3}, c \mathrm{NaCl}, d \mathrm{AlN} / \mathrm{Al}_{5} \mathrm{O}_{6} \mathrm{~N}$

metals in FAD, and consequently in the TCLP leachates, has been attributed to their fast volatilization (as they present low boiling point) during the scrap melting process (thus becoming part of the exhaust gases) and subsequently to their lower condensation temperature in the final FAD. $\mathrm{Al}, \mathrm{Ba}, \mathrm{Cr}, \mathrm{Ni}$ and Co presented higher extraction in case of $\mathrm{CAD}$, whereas the leaching of FAD resulted in higher values of $\mathrm{Zn}, \mathrm{As}$ and $\mathrm{Cu}$ in the leachates. Although the concentrations of the other metals were below the corresponding EPA limits, aluminium and zinc also presented high leaching values (no regulatory limit is available).

The results of the EN12457-2 leaching test for both dusts are presented in Table 4 . The final $\mathrm{pH}$ after leaching procedure, in both cases, was measured as 6.0, and no precipitates were observed. All heavy metals concentrations in the leachates were significantly lower, in relation with TCLP test, as the metals extraction efficiency varied significantly due to the different leaching conditions. Regarding the heavy metals leaching, it is obvious that neither CAD nor FAD can be classified in the inert waste category. In case of cyclone dust, only $\mathrm{Pb}$ was found to be above the corresponding regulatory limit, although the $\mathrm{Al}$ value in the leach liquor was also high (no regulatory limit is available), mainly due to the dissolution of water-soluble phases such as aluminium nitrites. Furthermore, the chlorides anions also exceeded the accepted limits. The corresponding high extraction values of sodium and potassium were a consequence of the $\mathrm{Cl}$ ions presence in the leachate, which were mainly combined with the form of soluble $\mathrm{Na}$ and $\mathrm{K}$ salts and were easily dissolved in the used leaching conditions. However, CAD could be disposed in landfills for hazardous waste, if the emission of the harmful gases from the decomposition of dust phases (nitrides, carbides, etc.) could be controlled.

On the other hand, the dust derived from the filters presented higher $\mathrm{Cd}, \mathrm{Pb}$ and $\mathrm{Cu}$ leaching values than the accepted limits for inert wastes, according to the 2003/33/ EC Directive (European Council, 2003), with the corresponding value for zinc to be marginally below the limit and the solubility of $\mathrm{Ba}, \mathrm{Cr}, \mathrm{Ni}$ and $\mathrm{Co}$ to be lower. The alkalis concentration in the leach liquor was significantly higher, in relation with the corresponding values of CAD, thus resulting in a much higher $\mathrm{Cl}$-ions quantity, whose 

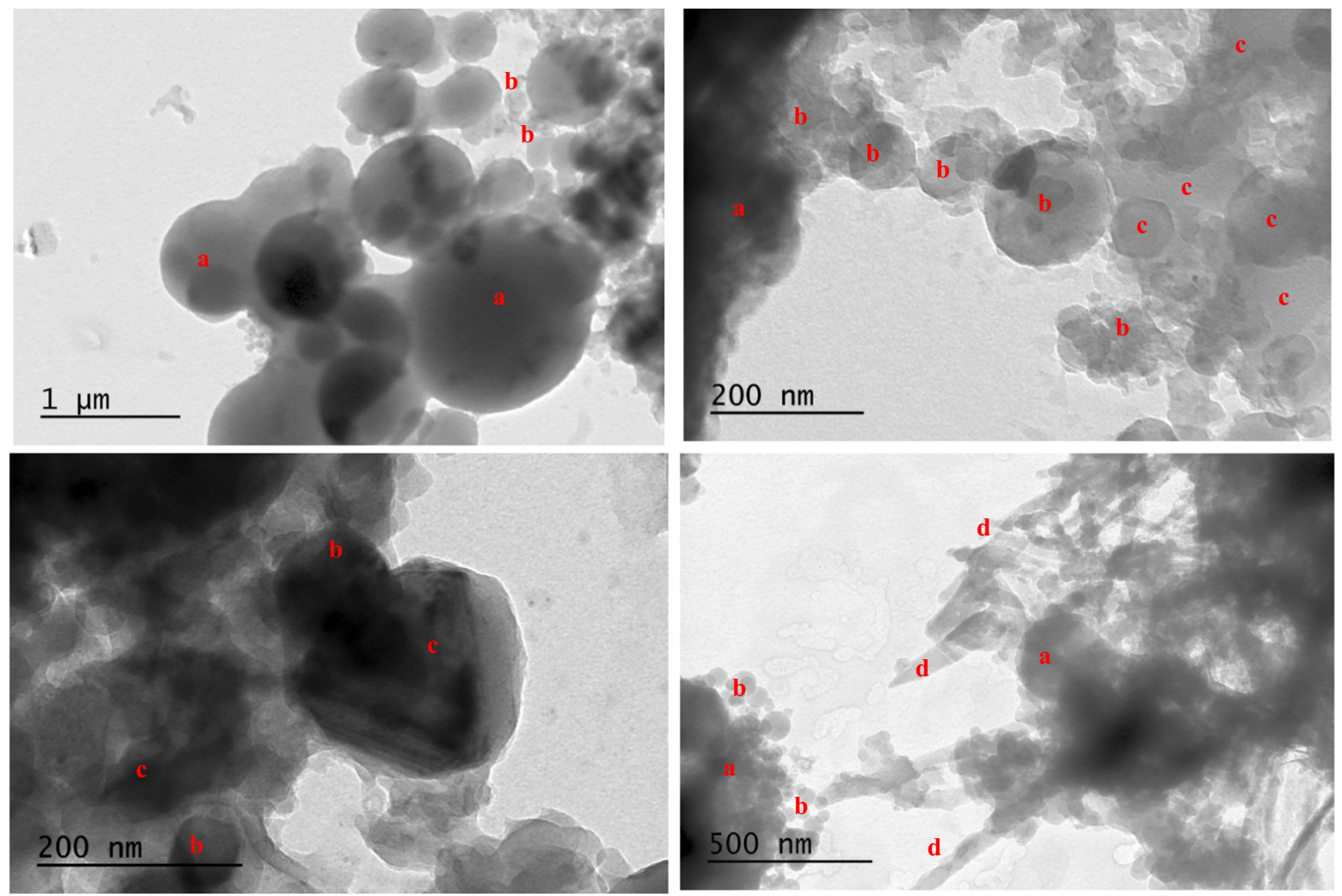

Fig. 6 Transmission electron microscopy micrographs of the as-received FAD. $a \mathrm{CaCO}_{3}, b \mathrm{Al}_{2} \mathrm{O}_{3}, c \mathrm{NaCl}, d \mathrm{AlN} / \mathrm{Al}_{5} \mathrm{O}_{6} \mathrm{~N}$

Table 3 TCLP results of aluminium dusts

\begin{tabular}{llll}
\hline $\begin{array}{l}\text { Metals of } \\
\text { concern }\end{array}$ & CAD $(\mathrm{mg} / \mathrm{L})$ & FAD $(\mathrm{mg} / \mathrm{L})$ & $\begin{array}{l}\text { EPA TCLP regulatory } \\
\text { limits }(\mathrm{mg} / \mathrm{L})\end{array}$ \\
\hline $\mathrm{Cd}$ & 0.30 & 1.75 & 1.0 \\
$\mathrm{~Pb}$ & 0.85 & 6.54 & 5.0 \\
$\mathrm{As}$ & 0.04 & 0.08 & 5.0 \\
$\mathrm{Ba}$ & 3.53 & 1.24 & 100 \\
$\mathrm{Cr}$ & 0.74 & 0.53 & 5.0 \\
$\mathrm{Al}$ & 116.5 & 29.7 & $\mathrm{NRL}$ \\
$\mathrm{Zn}$ & 27.4 & 67.7 & $\mathrm{NRL}$ \\
$\mathrm{Ni}$ & 0.65 & 0.32 & $\mathrm{NRL}$ \\
$\mathrm{Co}$ & 0.53 & 0.08 & $\mathrm{NRL}$ \\
$\mathrm{Cu}$ & 1.05 & 1.64 & $\mathrm{NRL}$ \\
\hline
\end{tabular}

$N R L$ no regulatory limits are available

concentration exceeded about 12 times the regulatory limit for inert wastes and it is significantly higher than the accepted limits, even for hazardous wastes.

Both leaching test results indicated that prior to both dusts disposal in safe landfills for inert and/or hazardous wastes, they should be processed, targeting at the removal
Table 4 Released metal concentration after EN 12457-2 leaching test at $L / S=101 / \mathrm{kg}$

\begin{tabular}{|c|c|c|c|c|}
\hline \multirow{2}{*}{$\begin{array}{l}\text { Metals of } \\
\text { concern }\end{array}$} & \multirow{2}{*}{$\begin{array}{l}\text { CAD } \\
(\mathrm{mg} / \mathrm{kg})\end{array}$} & \multirow{2}{*}{$\begin{array}{l}\text { FAD } \\
(\mathrm{mg} / \mathrm{kg})\end{array}$} & \multicolumn{2}{|c|}{ 200/33/CE } \\
\hline & & & $\begin{array}{l}\text { Inert } \\
(\mathrm{mg} / \mathrm{kg})^{\mathrm{a}}\end{array}$ & $\begin{array}{l}\text { Hazardous } \\
(\mathrm{mg} / \mathrm{kg})^{\mathrm{a}}\end{array}$ \\
\hline $\mathrm{Cd}$ & 0.08 & 0.11 & 0.04 & 5 \\
\hline $\mathrm{Pb}$ & 0.52 & 5.7 & 0.5 & 50 \\
\hline As & 0.09 & 0.35 & 0.5 & 25 \\
\hline $\mathrm{Ba}$ & 2.5 & 1.24 & 20 & 300 \\
\hline $\mathrm{Cr}$ & 0.28 & 0.08 & 0.5 & 70 \\
\hline $\mathrm{Al}$ & 540.3 & 120.4 & NRL & NRL \\
\hline $\mathrm{Zn}$ & 1.33 & 3.7 & 4 & 200 \\
\hline $\mathrm{Ni}$ & 0.5 & 0.2 & 0.4 & 40 \\
\hline Co & 0.03 & 0.01 & NRL & NRL \\
\hline $\mathrm{Cu}$ & 1.62 & 5.87 & 2 & 100 \\
\hline $\mathrm{Na}$ & 6280 & 23,470 & NRL & NRL \\
\hline K & 960 & 4980 & NRL & NRL \\
\hline $\mathrm{Cl}^{-}$ & 9850 & 37,200 & 800 & 25,000 \\
\hline
\end{tabular}

$N R L$ no regulatory limits are available

a Leaching limit values apply for waste acceptable at landfills for inert or hazardous wastes 
of water-soluble chlorides, which are mainly bounded with the form of halite and sylvite. In case of improper disposal, leaching of toxic metal ions into ground water would cause serious pollution problems. Except leachability, one other problem is the dusts reactivity with water (and humidity in air) which can lead to the formation of harmful or poisonous and unpleasant odorous gases, such as $\mathrm{NH}_{3}, \mathrm{CH}_{4}, \mathrm{PH}_{3}, \mathrm{H}_{2}$, $\mathrm{H}_{2} \mathrm{~S}$, etc. Consequently, recycling and recovery of valuables from such wastes may be the only alternative. Processes similar to the aluminium black dross or salt slag treatment and recycling could be used in case of aluminium dusts (cyclones or filters) too. Processes that include aluminium metal recovery by sieving, dissolving of water-soluble phases and use of the non-metallic residue in the building material sector (cement, ceramic, etc.) or in chemical/ metallurgical industry will reduce the cost of disposal and will also lead to less environmental problems (López et al. 2001; López-Delgado et al. 2009; Fiore et al. 2005).

\section{Conclusion}

Based on the data presented in this paper, a characterization and leachability study of two different types of secondary aluminium dusts, derived from the waste gases de-dusting system (cyclones and bag filters), was carried out. Regarding particle size distribution, about $90 \mathrm{wt} \%$ of the CAD exhibited a grain size smaller than $80 \mu \mathrm{m}$, whereas $50 \mathrm{wt} \%$ was below $22 \mu \mathrm{m}$. On the other hand, FAD presented a finer particle size with $90 \mathrm{wt} \%$ under $13.5 \mu \mathrm{m}$ and $50 \mathrm{wt} \%$ below $3.6 \mu \mathrm{m}$. Corundum $\left(\mathrm{Al}_{2} \mathrm{O}_{3}\right)$, spinel $\left(\mathrm{MgAl}_{2} \mathrm{O}_{4}\right)$, calcite $\left(\mathrm{CaCO}_{3}\right)$, halite $\mathrm{NaCl}$ and metallic $\mathrm{Al}$ were identified as the major phases of $\mathrm{CAD}$, whereas lower quantities of aluminium nitrides were also detected. The increased content of the salts (especially $\mathrm{NaCl}$ ), as well as the corresponding of $\mathrm{CaCO}_{3}$ in filter dust, was the main difference observed. Although all examined metals concentrations in the TCLP leach liquor were found to be below the regulatory limits in the case of CAD, aluminium extraction was significantly higher, mainly due to the aluminium nitrides leaching. On the other hand, FAD presents higher potential to exhibit toxicity characteristics, especially for $\mathrm{Cd}$ and lead. Both dusts presented high extraction values, especially for sodium, potassium and chlorides ions, during the EN12457-2 leaching test, where all water-soluble salts (chlorides and nitrites) were dissolved. Although CAD could be disposed in landfills for hazardous wastes, the chlorides content in case of FAD exceeded the accepted limits even for hazardous wastes. As a result, the disposal of such wastes, even in landfills for hazardous wastes, requires a primary treatment for the removal of water-soluble phases, and the choice of recycling, after reprocessing, as a raw material seems to be the only sustainable alternative.
Acknowledgments The Authors would like to express their warmest thanks to The Electron Microscopy Center of the National Technical University of Athens for the detailed microstructure study.

\section{References}

Aluminium Association (2013) The environmental footprint of semifinished aluminum productions in North America

Calder GV, Stark TD (2010) Aluminum reactions and problems in municipal solid waste landfills. Pract Period Hazard Tox Radioact Waste Manage 14:258-265

Dirgo JA, Cooper DW (1983) Theoretical investigation of pressure drop in combined cyclone and fabric filter systems. Atmos Environ 17:161-167

EN-12457-2 (2003) Characterization of waste, leaching-compliance test for leaching of granular waste materials and sludges. Part 2. One stage batch test at a liquid to solid ratio of $10 \mathrm{l} / \mathrm{kg}$ for materials with particle size below $4 \mathrm{~mm}$ (without or with size reduction)

EPA (1992) Toxicity characteristics leaching procedure (TCLP), method 1311, U.S. Environmental Protection Agency, USA

European Aluminium Association (2004) Aluminium recycling in Europe. The road to high quality products, EAA, Brussels

European Council 33 (2003) Council Decision of 19 December 2002 establishing criteria and procedures for the acceptance of waste at landfills pursuant to Article 16 of an Annex II to Directive 1999/31/EC, Official Journal L 011, 16/01/2003, pp 0027-0049

European Waste Catalogue and Hazardous Waste List (2002) Environmental Protection Agency, Ireland, Valid from 1 January 2002

Fiore S, Zanetti MC, Ruffino B (2005) Waste characterization and recycle in an aluminium foundry. Resour Conserv Recycl 45:48-59

Huang XL, El Badawy AM, Arambewela M, Adkins R, Tolaymat T (2015) Mineral phases and metals in baghouse dust from secondary aluminum production. Chemosphere 134:25-30

International Aluminium Institute (2013) Global aluminium recycling: a cornerstone of sustainable development. Global Aluminium Recycling Committee, IAI, London

López FA, Pena MC, López-Delgado A (2001) Hydrolysis and heat treatment of aluminum dust. J Air Waste Manage Assoc 51:903-912

López-Delgado A, Tayibi H, Pérez C, Alguacil FJ, López FA (2009) A hazardous waste from secondary aluminium metallurgy as a new raw material for calcium aluminate glasses. J Hazard Mater 165:180-186

Peukert W, Wadenpohl C (2001) Industrial separation of fine particles with difficult dust properties. Powder Technol 18:136-148

Shinzato MC, Hypolito R (2005) Solid waste from aluminium recycling process: characterization and reuse of its economically valuable constituents. Waste Manage 25:37-46

Strauss W (1975) Industrial gas cleaning, 2nd edn. Pergamon Press, Oxford, England

Tenorio JAS, Espinosa DCR (2002) Effect of salt/oxide interaction on the process of aluminum recycling. J Light Met 2:89-93

Tsakiridis PE (2012) Aluminium salt slag characterization and utilization-a review. Hazard Mater 217-218:1-10

Tsakiridis PE, Oustadakis P, Agatzini-Leonardou S (2013) Aluminium recovery during black dross hydrothermal treatment. J Environ Chem Eng 1:23-32

Unger TW, Beckmann M (1992) Salt slag processing for recycling, light metals. In: Proceedings of sessions, TMS Annual Meeting, San Diego, California, pp 1159-1162

Vallero DA (2008) Fundamentals of air pollution. Elsevier: Academic Press, Amsterdam

Wernick IK, Themelis NJ (1998) Recycling metals for the environment. Annu Rev Energy Env 23:465-497 